\title{
THE BACTERIOPHAGES OF BACILLUS MEGATERIUM
}

\author{
I. Serological, Physical, and Biological Properties \\ MURRAY FRIEDMAN ${ }^{1,2}$ AND PHILIP B. COWLES \\ Department of Microbiology, Yale University, New Haven, Connecticut \\ Received for publication March 23, 1953
}

Research on bacterial viruses has been stimulated in recent years by realization that their study may give some insight into the general problem of virus-host relationships. It is of interest to note that Henle and Henle (1947) have pointed out a number of striking similarities between certain bacterial viruses and those causing influenza. The analogies were most apparent in the phenomena of adsorption and of interference, as well as in effects on the metabolism of the host. Subsequently, Henle et al. (1947) reported one step multiplication curves for the influenza virus, and more recently Briody and Stannard (1951) have indicated that vaccinia virus increases similarly.

The bacteriophage-bacterium relationship offers to investigators simple manipulative procedures for the study of host-virus systems, and advantage has been taken of this to the fullest extent in the investigations of the $\mathrm{T}$ system of Escherichia coli (Demerec and Fano (1945)). The seven viruses comprising this group have been examined biologically, physically, and chemically; and most of our information concerning bacterial host-virus relationships has been derived from this research. Investigations concerning some members of the " $T$ " phages were carried out as early as 1939 by Ellis and Delbrück and have been conducted with increasing momentum since then. In view of the notable contributions which these studies have made, it seemed that investigation of another system might be rewarding, in part as a means of determining how uniform are viral characteristics and host-virus relationships.

The host-virus system chosen for study is one which is rather far removed in the bacterial kingdom from the coli-dysentery group and con-

1 This paper is based on this author's doctorate thesis deposited in the Yale University library.

2 Present address: Division of Biophysics, Sloane Physics Laboratory, Yale University, New Haven, Connecticut. sists of Bacillus megaterium as host and five phages which are capable of attacking it.

\section{MATERIALS AND METHODS}

The bacterial culture used throughout this investigation is a virus sensitive asporogenous strain of Bacillus megaterium, which serves as both indicator and host for the bacterial viruses studied. This culture was obtained originally from Dr. A. D. Hershey and has been maintained in the stock culture collection of this department for a number of years. It seems to be very similar to den Dooren de Jong's " $\mathrm{Mu}$ tilate", no. $338 \mathrm{~b}$, also an asporogenous strain. In this paper, this particular strain is designated $B$. megaterium, strain $\mathrm{S}$ (sensitive), and the abbreviation $\mathrm{S}$ will be used to denote the culture.

The five bacterial viruses investigated have been designated M1, M2, M3, M4, and M5. M1 was derived from culture filtrates of $B$. megaterium, strain 899; the others were isolated from soil samples using strain $\mathrm{S}$ as the bacterial host. All virus stocks were purified by three successive single plaque isolations.

Broth routinely used was composed of yeast extract (Difco), $10 \mathrm{~g}$, and tryptose (Difco), $2 \mathrm{~g}$ per liter of distilled water, adjusted to $\mathrm{pH}$ 7.2. The hard agar base for plates was composed of $13 \mathrm{~g}$ of agar added to a liter of broth, and $7 \mathrm{~g}$ of agar per liter of broth made up the soft agar. The plating method of Gratia (1936) was used with slight modification for phage assay.

Antisera to the five phages were produced in rabbits by inoculating $30 \mathrm{ml}$ of $10^{10}$ virus subcutaneously over a period of two weeks. All sera were heated at $56 \mathrm{C}$ for 30 minutes before use.

\section{EXPERIMENTAL RESULTS}

Serological characteristics. Serology has become an important criterion for classifying bacterial viruses (Adams, 1952); and on the basis of 
neutralization reactions, Delbrück (1946) has suggested that serological characteristics of the "T" phages are sufficient to divide these viruses into genetically distinct groups. Neutralization reactions were carried out with the " $M$ " phages with homologous and heterologous antisera to determine possible serological relationships among these viruses. Antiserum to M1 was capable of neutralizing M2 and M3 as well but was without effect on M4 or M5. It may be noted (figure 1) that the homologous reaction appears to be

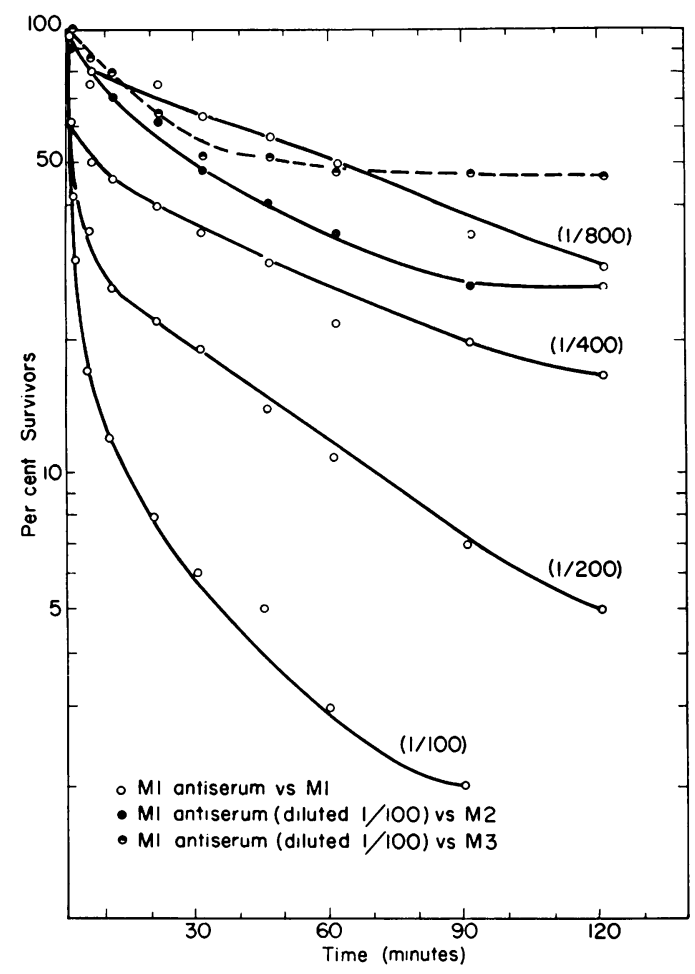

Figure 1. Neutralization of M1, M2, and M3 with varying dilutions of M1 antiserum.

stronger than the heterologous neutralizations. The antiserum produced against M2 neutralized M3 as well although it was without effect on the other three viruses even in $1 / 10$ dilution with 24 hours' incubation. Neutralization reactions involving antiserum to M3 indicated that it was capable of neutralizing M2 also.

The antisera produced against M4 and M5 appear to be specific for their respective phages as they failed to neutralize any heterologous virus. The neutralization reactions suggest that there are at least 3 distinct immunological groups with nonreciprocal cross-neutralization between M1 and the M2, M3 pair.

Electron microscope morphology. Viral preparations to be photographed were obtained by lysing with each virus heavy concentrations of the bacterial host. The titers of the raw lysates were approximately $10^{10}$ per $\mathrm{ml}$ after filtration through Chamberland L5 candles. The viral solu-

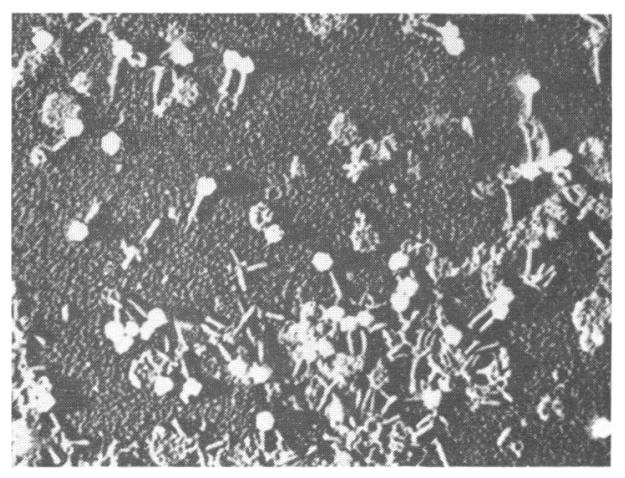

Figure 2. Electron photomicrograph of M4 shadowed with palladium.

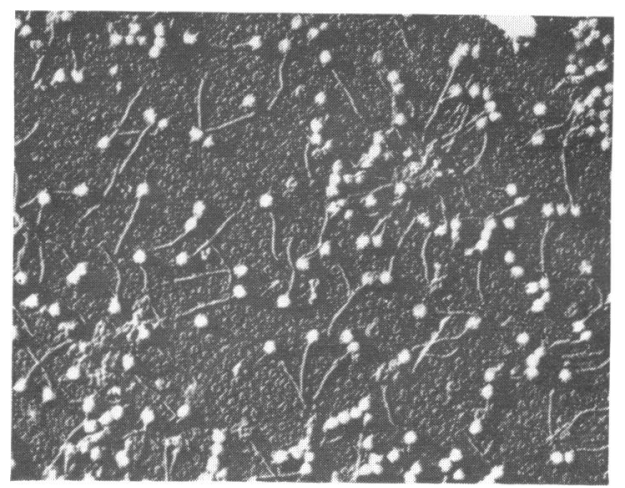

Figure 3. Electron photomicrograph of M5 shadowed with palladium.

tions were centrifuged three times in distilled water at $26,000 \mathrm{G}$ for one hour and 3,000 $\mathrm{G}$ for 10 minutes differentially to concentrate and purify them. After the final concentration the viral suspensions were pipetted onto collodion nickel grids and shadowed with palladium. The size of each virus was obtained by measuring the virus image photograph on the plate with a calibrated eye-piece and dividing the values obtained by the magnification factor of the microscope.

Figures 2 and 3 illustrate the two representa- 
tive morphologies which were found for the "M" phages. Viruses M1, M2, M3, and M5 appear to have the same appearance. There were slight dimensional variations among the four and these values (corrected for shadowing) are given in table 1. M4 seems to have a com-

\section{TABLE 1}

Sizes of the " $M$ " phages as determined by the electron microscope

\begin{tabular}{c|c|c}
\hline VIRUS & IEAD A & IAII A \\
\hline M1 & 620 & 2,900 \\
M2 & 610 & 2,900 \\
M3 & 610 & 2,900 \\
M4 & 950 & 1,800 \\
M5 & 700 & 3,000 \\
\hline
\end{tabular}

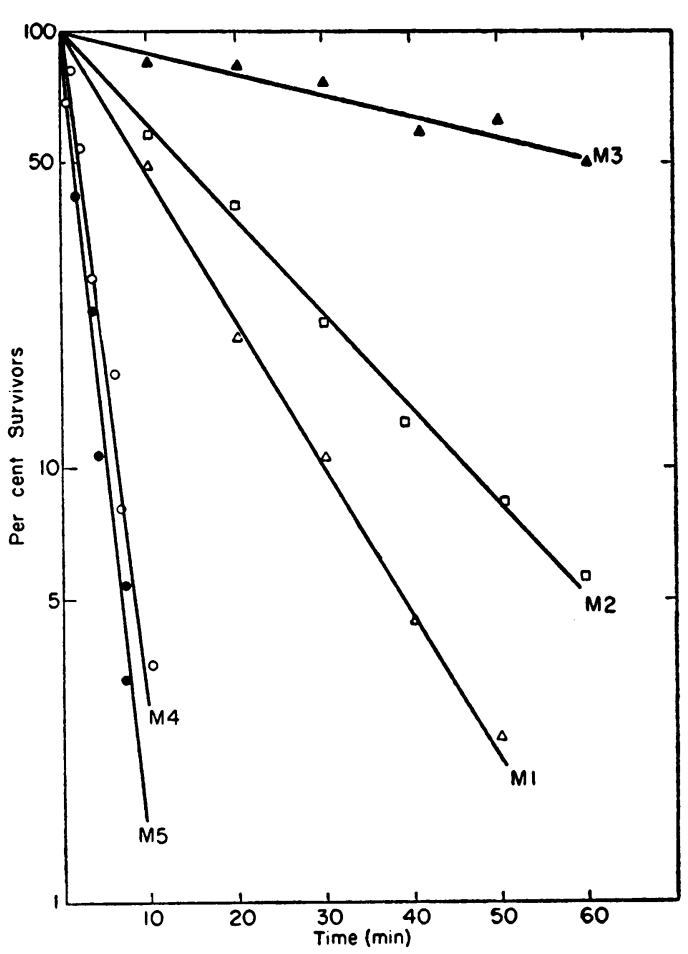

Figure 4. Logarithmic inactivation of the " $\mathrm{M}$ " phages at $60 \mathrm{C}$.

pletely different morphology as well as significant dimensional differences from the other phages. The most striking difference is the short thick tail of M4 which is in marked contrast to the long slender tails of the others.

Thermal inactivation. All inactivations were performed in broth, in a water bath at $37 \pm 0.5$
C. Viral solutions were pipetted into tubes fitted with tight rubber stoppers. All tubes were submerged completely during the inactivation and were plunged immediately into ice water after the specified time of heating. For short term inactivations, $0.1 \mathrm{ml}$ of concentrated phage was added to $9.9 \mathrm{ml}$ broth at the desired temperature. The rate of inactivation is followed by plotting the $\log$ of the per cent survivors against time.

Figure 4 shows the typical exponential inactivations of the " $M$ " phages at $60 \mathrm{C}$. The Arrhe-

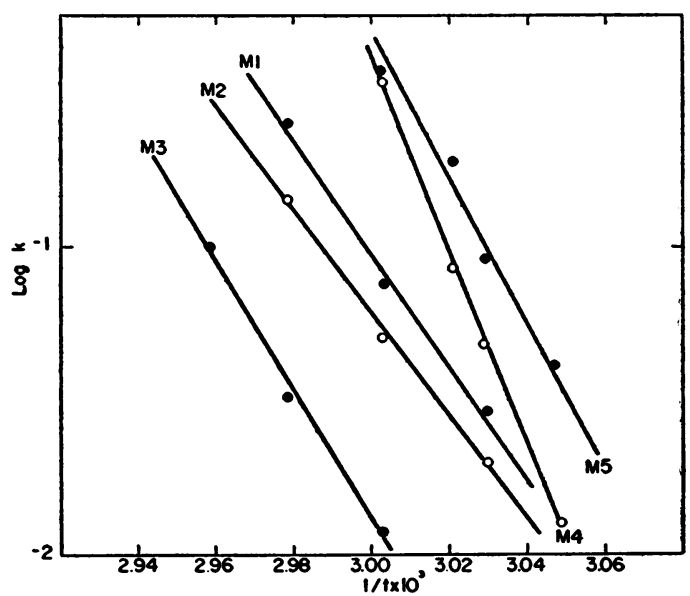

Figure 5. The log of the velocity constant plotted against the reciprocal of the absolute temperature for the " $M$ " phages.

nius equation may be used to derive $\Delta H$, the heat of activation.

(a) $\quad \log K=\frac{\Delta H}{2.3 R \cdot T}+$ constant

$\Delta F$ at $60 \mathrm{C}$ was calculated by use of the formula given by Pollard and Reaume (1951)

(b) $\Delta F=4.58 T(10.318+\log T-\log K)$

and the change in entropy $(\Delta S)$ at $60 \mathrm{C}$ is given by the expression

$$
\Delta S=\frac{\Delta H-\Delta F}{T}
$$

These data are presented in figure 5 and table 2. It appears that M1, M2, and M3, which are related serologically, have similar thermal constants, while the constants for M4 and M5 appear to differ significantly from one another and from those of the other group of phages. 
The data in table 2 suggest that there may be a correlation between serological type and the $\Delta H$ values. Adams (1949a) has shown that some bacterial viruses which are related serologically have comparable $\Delta H$ values when thermally inacti-

TABLE 2

Constants for thermal inactivation of the " $M$ " phages

\begin{tabular}{c|c|c|c|c|c}
\hline PHAGE & $\mathrm{C}$ & $k$ & $\Delta F$ & $\Delta B$ & $\Delta S$ \\
\hline M1 & 57 & $1 / 35$ & & & \\
& 60 & $1 / 13$ & 21,100 & 76,000 & 165 \\
& 62.5 & $1 / 4$ & & & \\
& 65 & $1 / 1.5$ & & & \\
\hline M2 & 57 & $1 / 50$ & & & \\
& 60 & $1 / 20$ & 21,200 & 92,500 & 183 \\
& 62.5 & $1 / 7$ & & & \\
& 65 & $1 / 2.5$ & & & \\
\hline M3 & 60 & $1 / 80$ & 22,500 & 87,500 & 195 \\
& 62.5 & $1 / 25$ & & & \\
& 65 & $1 / 10$ & & & \\
\hline M4 & 55 & $1 / 80$ & & & \\
& 57 & $1 / 21$ & & & \\
& 58 & $1 / 12$ & & & \\
& 60 & $1 / 3$ & 20,300 & 136,000 & 347 \\
\hline M5 & 55 & $1 / 25$ & & & \\
& 57 & $1 / 11$ & & & \\
& 58 & $1 / 5$ & & \\
& 60 & $1 / 2.5$ & 20,000 & 112,000 & 254 \\
\hline
\end{tabular}

TABLE 3

Per cent survivors of the " $M$ " phages in broth at s7 $C$ for one hour at various $p H$ 's

\begin{tabular}{l|r|r|r|r|r|r|r}
\hline & \multicolumn{7}{|c}{ pH } \\
\cline { 2 - 7 } & \multicolumn{1}{|c|}{4} & 5 & 6 & 7 & 8 & 9 & 10 \\
\hline M1 & 0 & 35 & 100 & 100 & 100 & 60 & 15 \\
M2 & 4 & 100 & 100 & 100 & 100 & 100 & 0 \\
M3 & 24 & 100 & 100 & 100 & 100 & 100 & 0 \\
M4 & 0 & 100 & 100 & 100 & 100 & 100 & 0 \\
M5 & 0 & 0 & 4 & 100 & 100 & 100 & 60 \\
\hline
\end{tabular}

vated in broth or in $0.1 \mathrm{~N}$ sodium chloride. That this relationship does not hold for dry thermal inactivation is indicated by the data of Pollard and Reaume (1951) who have shown that in such a reaction the $\Delta H$ values for serological unrelated viruses are very similar. $p H$ stability. To determine the relative $p H$ stabilities of the "M" viruses, samples of autoclaved broth were adjusted to the desired value. Virus dilutions, made with broth of the proper $\mathrm{pH}$, were incubated in a water bath at $37 \mathrm{C}$ for one hour, after which time they were assayed for infectivity.

The results presented in table 3 indicate that the infectivity of M2, M3, and M4 is destroyed on the alkaline side, with a change of one $\mathrm{pH}$ unit from 9 to 10. M1 and M5 appear to be more stable at higher $\mathrm{pH}$ 's although $\mathrm{M} 1$ is 30 per cent inactivated at $\mathrm{pH} 9$. In the acid region $\mathrm{M} 1$ and M5 are more sensitive; M5 shows no infectivity at $\mathrm{pH} 5$, and M1 is more than 60 per cent inactivated at this $\mathrm{pH}$. In contrast M2, M3, and M4 have complete stability at $\mathrm{pH} 5$ during the time used.

Sonic inactivation. Bacterial viruses appear to vary in their sensitivity to intense sonic vibration. Anderson et al. (1948) studied the effects of sonic vibrations on members of the " $T$ " system and found that $\mathrm{T} 2, \mathrm{~T} 4, \mathrm{~T} 5$, and $\mathrm{T} 6$ were inactivated most rapidly. These viruses are relatively large in comparison to $\mathrm{T} 1, \mathrm{~T} 3$, and $\mathrm{T} 7$ which are most resistant to this type of inactivation. It was suggested that sensitive viruses, with their large and complex structures, are disintegrated mechanically by intense sonic energy, and that smaller viruses offer a more resistant structure. Sonic inactivation of the " $M$ " phages was carried out in order to determine any differences in their resistances and, in addition, to examine Anderson's hypothesis. Ten $\mathrm{ml}$ of broth diluted samples of each " $M$ " phage were treated separately in the water cooled container of a Raytheon magnetostriction sonic oscillator (R-22-3) which produced a frequency of 9,000 cycles per sec. Samples were removed at the desired time and were assayed on the indicator. In order to relate the results to Anderson's investigations, two " $\mathrm{T}$ " phages ( $\mathrm{T} 1$ and T5) were included into the experiment. $\mathrm{T} 1$ is reported to be the more resistant of the two to sonic inactivation.

Figure 6 shows the relative sensitivities of the " $M$ " phages and of the two " $T$ " viruses. The " $M$ " phages as a group are inactivated rapidly at a logarithmic rate by the sonic vibration, and they appear to be more sensitive than the sonic resistant members of the " $T$ " phages. However, it can be observed that there are varying sensitivities to sonic action among the " $M$ " phages 
themselves. M4 and M5 are the most rapidly inactivated while the sensitivities of M2 and M3 are comparable to that of T5. Although the sizes of the " $T$ " phages have been considered by Anderson et al. (1948) to be the determining factor in their relative sensitivities to sonic inactivation, the data here indicate that this is not true for the " $M$ " phages. While electron micrographs of M4 and M5 suggest distinct morphological differences, their inactivation rates are relatively the same. On the other hand, M1, M2, M3, and M5 are similar in morphology, yet M5 shows a much greater sonic sensitivity than do the others.

Latent period and burst size. The methods for determining latent period and burst size (Adams, 1950) have been modified to some extent. Latent periods were determined by inoculating $10 \mathrm{ml}$ of shake culture containing $5 \times 10^{7}$ indicator cells per $\mathrm{ml}$ held at $35 \mathrm{C}$, with $0.1 \mathrm{ml}$ of broth containing $4 \times 10^{5}$ virus particles. One-tenth $\mathrm{ml}$ of this mixture was plated out at various time intervals, and a sharp increase in virus titer could be observed as a time characteristic of each virus. Burst-size determinations were carried out by diluting a similar mixture $\left(5 \times 10^{7}\right.$ bacteria per ml) 10 minutes before the end of respective latent period. This reduced the phage concentration to a point where $10 \mathrm{ml}$ of the dilution would contain six plaque producing units. The diluent used was an $\mathrm{S}$ broth culture filtrate. One $\mathrm{ml}$ of the dilution was pipetted on to an agar plate and incubated for no more than $11 / 2$ times the latent period. The plates were covered then with $2 \mathrm{ml}$ of 1 per cent soft agar seeded with indicator and incubated at $35 \mathrm{C}$ for 18 hours.

Burst size averages for each virus, based on 50 plates for each, and latent periods are shown in table 4.

There was some variation in extreme upper and lower ranges of burst sizes for all the phages, but this did not exceed a factor of five.

On the other hand, there is considerable variation in the latent periods of the five viruses, and it may be noted that M1, M2, and M3 have much longer periods than do M4 and M5. The latent periods are of interest because in each case the observed period is greater than the generation time of the host (40 minutes). This does not hold for the "T" phages since $T 1, T 3$, and T7 have shorter latent periods than the host's generation time.
Effect of citrate. Citrate ion has been shown to inhibit the growth of certain bacterial viruses by interfering with calcium utilization, and this was regarded as an important property by Burnet (1933). At one time a classification was proposed which would place bacterial viruses into

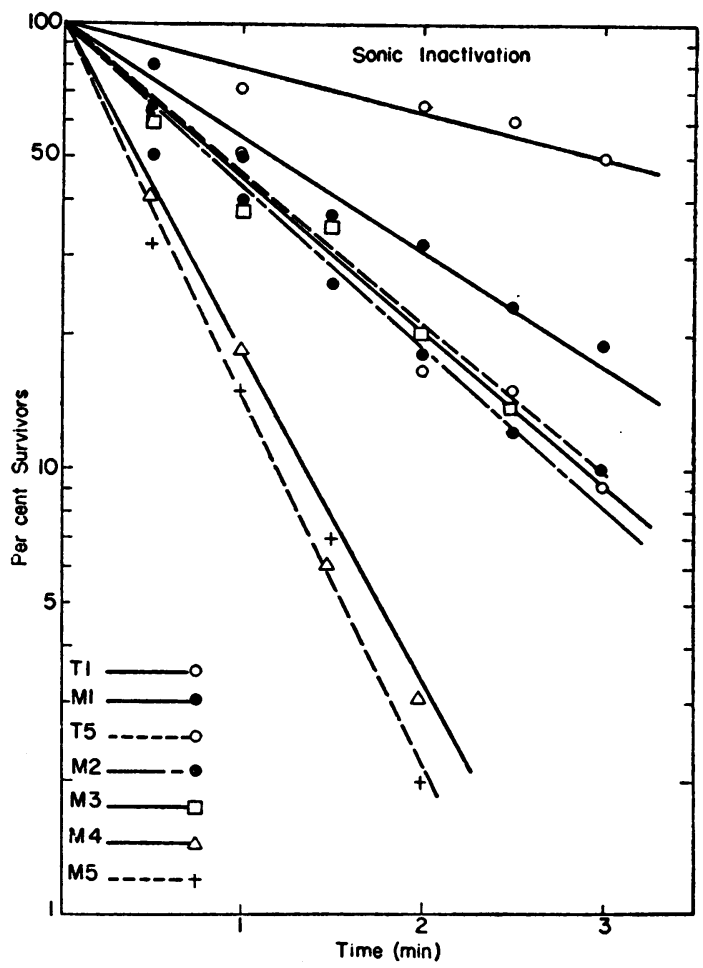

Figure 6. Per cent survivors of the " $M$ " phages and $\mathrm{T} 1$ and $\mathrm{T} 5$ after sonic treatment.

TABLE 4

Burst sizes and latent periods of the " $M$ " phages

\begin{tabular}{c|c|c}
\hline VIRUS & BURST SIIX & LATINT PERIOD \\
\cline { 2 - 3 } M1 & & min \\
M2 & 105 & 93 \\
M3 & 95 & 117 \\
M4 & 110 & 93 \\
M5 & 122 & 58 \\
\hline
\end{tabular}

two groups, those which were citrate sensitive and those which were not. Adams (1949b) has shown that $\mathrm{T} 1$ and $\mathrm{T} 5$ required calcium ion in much higher concentration than did the other "T" phages. Sodium citrate was added to both the semisolid and the hard agar media to provide two different concentrations, 0.1 per cent $(0.004 \mathrm{M})$ and 1 per cent $(0.04 \mathrm{M})$. 
The data in table 5 show that the viruses are inhibited in different degrees in the presence of citrate. M1 is the most sensitive since it is inactivated completely at 0.1 per cent concentration. M2 and M3 react similarly, while M4 is the least inhibited by citrate.

Host resistance. The use of hosts resistant to virus infection is valuable in many types of investigation. Stable subcultures of $S$ resistant to M1 and M5, respectively, were obtained by inoculation of a broth culture containing $10^{\circ} \mathrm{ml}$ cells with $10^{6} \mathrm{ml}$ virus. $\mathrm{S} / 1$ was attacked by all the viruses, with the exception of M1, with no loss

TABLE 5

Citrate inhibition of phages titering $10^{8}$

\begin{tabular}{|c|c|c|}
\hline PEAGX & $\begin{array}{l}\text { 0.1 PRR CENT } \\
\text { CITRATE REDUCTION } \\
\text { IN LOG TITER }\end{array}$ & $\begin{array}{c}1 \text { PIR CENT } \\
\text { CITRATI REDUCTION } \\
\text { TN LOG TITER }\end{array}$ \\
\hline M1 & 8 & 8 \\
\hline M2 & 2 & 8 \\
\hline M3 & 2 & 8 \\
\hline M4 & 0.7 & 2 \\
\hline M5 & 1 & 8 \\
\hline
\end{tabular}

1950; Clarke and Cowles, 1952) that spontaneous lysis occurs only in a small fraction of cells in culture 899. Another paper deals more fully with this point (Cowles, 1953).

\section{DISCUSSION}

Examination of data for the "M" system (table 6) reveals a number of interesting points. The serological reactions of the " $M$ " phages show nonreciprocal cross-neutralization between M1, and M2 and M3, a phenomenon not previously reported for bacterial viruses. Antisera for M2 and M3, however, did show cross-neutralization with their respective phages which was reciprocal and which followed the usual cross-reaction pattern. If M1, M2, and M3 are considered to be a serological group, then their similar morphologies tend to confirm the contention of Delbrück (1946) and Adams (1952) that the two properties are coincident.

The experiments on heat inactivation show that the thermal constants of M1, M2, and M3 are similar even though their relative sensitivities to heat are different. Attention is called

TABLE 6

Viral characteristics of the " $M$ " system

\begin{tabular}{|c|c|c|c|c|c|c|c|c|}
\hline PHAGE & SEROLOGY & SIZI IN ANGSTROYS & $\operatorname{mEAT} \Delta S$ & $\underset{\substack{\mathrm{pH} \\
\text { STABHITY } \\
\text { RANGI }}}{\mathrm{pANG}}$ & $\begin{array}{c}\text { SoNIC } \\
\text { SENSITIVITY }\end{array}$ & $\begin{array}{l}\text { LATENT } \\
\text { PERIOD }\end{array}$ & $\underset{\text { SENSITIVITY }}{\text { CITRATI }}$ & $\begin{array}{c}\text { STABLE } \\
\text { PIISISTANT HOST } \\
\text { TORMATION }\end{array}$ \\
\hline & & & & & & $\min$ & & \\
\hline M1 & AA & $620 \times 2,900$ & 165 & $5-10$ & + & 93 & ++++ & + \\
\hline M2 & A & $610 \times 2,900$ & 183 & 4-9 & ++ & 117 & +++ & - \\
\hline M3 & $\mathbf{A}$ & $610 \times 2,900$ & 195 & 4-9 & ++ & 93 & +++ & - \\
\hline M4 & B & $950 \times 1,850$ & 347 & $5-9$ & ++++ & 58 & + & - \\
\hline M5 & C & $700 \times 3,000$ & 254 & $6-10$ & +++ & 62 & ++ & + \\
\hline
\end{tabular}

in plating efficiency as compared to $\mathrm{S}$. $\mathrm{S} / 5$ showed similar characteristics. These cultures, in the process of becoming resistant, also become lysogenic for the inducing virus.

Numerous attempts to produce stable $S$ cultures resistant to viruses M2, M3, and M4 failed. Any resistant bacterial growth which did result underwent spontaneous lysis after 18 hours and was completely destroyed. The acquisition of resistance of the host to M1 or to M5 does not make it immune to attack by any of the other four viruses. The spontaneous lysis of these resistant (and lysogenic) substrains of $S$ is not so characteristic of other cultures of $B$. megaterium. It has been shown (Lwoff and Gutmann, also to the latent period of the viruses, for here again M1, M2, and M3 show similar characteristics. The relationship between morphology and other properties is not always maintained, however. M5 in its morphology is very similar to the other viruses, and yet its properties appear to be completely different.

Data for M4 show that it is quite distinct from the other " $M$ " phages. In addition to its lack of serological relationship to the other viruses, its morphology, thermal constants, and citrate resistance set it apart although its sonic sensitivity seemed to be identical with that of M5.

It would seem that there exist enough differences between the characteristics of these 5 
megaterium viruses and those of the " $T$ " series to make this " $M$ " series a profitable group to study in more detail.

\section{ACKNOWLEDGMENT}

The authors wish to acknowledge the assistance of Dr. W. H. Gaylord in the preparation of the electron micrographs.

\section{SUMMARY}

A new bacterial host-virus system, the " $M$ " system, comprising five bacterial viruses (M1, M2, M3, M4, M5) and a single host has been investigated. The serological, physical, and biological characteristics of these viruses have been studied. The neutralization reactions indicate the existence of three immunological groups composed of (a) M1, M2, M3, (b) M4, (c) M5. There is evidence of nonreciprocal cross-neutralization between the M1 virus and the M2 and M3 phages. Electron photomicrographs suggest that M1, M2, M3, and M5 are similar in morphologies and dimensions, while M4 appears to be different from the others. The results of the thermal inactivation of the viruses suggest a possible correlation between serological type and thermal reaction constants. Among the five "M" phages differences have been found in virus-host relationships and in latent periods. There appears to be no great variation in burst sizes. It has been suggested that the " $M$ " system be utilized for study since some of its characteristics are unique for bacterial-virus systems.

\section{REFERENCES}

Adams, M. H. 1949a The stability of bacterial viruses in solutions of salt. J. Gen. Physiol., 32, 579-594.

Adams, M. H. $1949 b \quad$ The calcium requirement of coliphage T5. J. Immunol., 62, 505-516.

AdAMs, M. H. 1950 Methods of study of bacterial viruses. In Methods in medical research. Vol. II. Year Book Publishers, Chicago, Ill.

Adams, M. H. 1952 Classification of bacterial viruses: Characteristics of the T5 species and of the T2, C16 species. J. Bact., 64, 387396.
Anderson, T. F., Boggs, S., And Winters, B. C. 1948 The relative sensitivity of bacterial viruses to intense sonic vibration. Science, 108, 18.

Briody, B. A., ANd Stannard, C. 1951 Studies on vaccinia virus. The development of hemagglutinating and infective particles in the chorioallantois of the chick embryo. J. Immunol., 67, 403-411.

Burnet, F. M. 1933 The classification of dysentery-coli bacteriophages. III. A correlation of the serological classification with certain biochemical tests. J. Path. Bact., 37, 179-184.

Clarke, N. A., and Cowles, P. B. 1952 Studies on the host-virus relationship in a lysogenic strain of Bacillus megaterium. I. The relationship between growth and bacteriophage production in cultures of Bacillus megaterium. J. Bact., 63, 177-186.

Cowles, P. B. 1953 Lysogenesis in Bacillus megatherium. Yale J. Biol. and Med., 25, 313-319.

DelBrück, M. 1946 Bacterial viruses or bacteriophages. Biol. Revs. Cambridge Phil. Soc., 21, 30-40.

Demerec, M., and Fano, U. 1945 Bacteriophage resistant mutants in Escherichia coli. Genetics, 30, 119-136.

Eluis, H. L., AND Delbrücr, M. 1939 The growth of bacteriophage. J. Gen. Physiol., 22, 365-384.

Gratia, A. 1936 Des relations numeriques entre bacteries lysogenes et particules de bacteriophage. Ann. inst. Pasteur, 51, 652-676.

Henle, W., ANd Henle, G. 1947 Interference between inactive and active viruses of influenza. V. Effect of irradiated virus on the host cells. Am. J. Med. Sci., 214, 529-541.

Henle, W., Henle, G., and Rosenberg, E. B. 1947 The demonstration of one-step growth curves of influenza viruses through the blocking effect of irradiated virus on further infection. J. Exptl. Med., 86, 423-437.

Lwoff, A., and Gutmann, A. 1950 La liberation de bacteriophages par la lyse d'une bacterie lysogene. Comp. rend., 230, 154156.

Pollard, E. C., and Reaume, M. 1951 Thermal inactivation of bacterial viruses. Arch. Biochem. Biophys., 32, 278-283. 